\title{
Viabilidade de Staphylococcus aureus FRI S-6 e produção de SEB em queijo elaborado com adição de Lactobacillus rhamnosus e Lactococcus lactis
}

\author{
[Staphylococcus aureus FRI S-6 viability and its SEB production in cheese produced with \\ Lactobacillus rhamnosus and Lactococcus lactis] \\ B. Seridan ${ }^{1}$, M.R. Souza ${ }^{2}$, J.R. Nicoli ${ }^{3}$, L.S. Carmo ${ }^{3}$, L.D.M. Menezes ${ }^{4}$, \\ D.L.S. Oliveira ${ }^{5}$, E.H.P. Andrade \\ ${ }^{1}$ Aluna de pós-graduação - EV-UFMG - Belo Horizonte, MG \\ ${ }^{2}$ Escola de Veterinária - Universidade Federal de Minas Gerais - Belo Horizonte, MG \\ ${ }^{3}$ Instituto de Ciências Biológicas - UFMG - Belo Horizonte, MG \\ ${ }^{4}$ IMA - Belo Horizonte, MG \\ ${ }^{5}$ Aluna de graduação - EV-UFMG - Bolsista FAPEMIG - Belo Horizonte, MG
}

\begin{abstract}
RESUMO
Staphylococcus aureus foi inoculado em queijos produzidos de forma estéril em laboratório, juntamente com Lactobacillus rhamnosus e Lactococcus lactis, isolados de queijo de coalho artesanal e identificados por PCR-ARDRA16S-23S. L. lactis foi capaz de reduzir a contagem de S. aureus no primeiro dia após produção $(\mathrm{P}<0,05)$ dos queijos de $3,3 \times 10^{7} \mathrm{UFC} / \mathrm{g}$ para $1,0 \times 10^{7} \mathrm{UFC} / \mathrm{g}$. L. rhamnosus não impediu o crescimento de $S$. aureus. A presença das cepas acidoláticas, principalmente L. lactis, mostrou ainda potencial de inibição da produção de enterotoxina estafilocócica do tipo B, sendo que a concentração de enterotoxinas no $15^{\circ}$ dia foi inferior ao limite de detecção pelo kit comercial utilizado. Concluiu-se que a presença das bactérias acidoláticas estudadas pode contribuir para a melhoria da qualidade sanitária de queijos artesanais.
\end{abstract}

Palavras-chave: queijo, Staphylococcus aureus, Lactococcus lactis, Lactobacillus rhamnosus, enterotoxinas, qualidade sanitária

\begin{abstract}
Staphylococcus aureus was inoculated in cheese elaborated with Lactobacillus rhamnosus and Lactococcus lactis, produced in a sterile lab, previously isolated from Brazilian coalho artisanal cheese and identified by PCR-ARDRA16S-23S. L. lactis was able to reduce the staphylococcal count on the first day after cheese production $(P<0.05)$ from $3.33 \times 10^{7} \mathrm{CFU} / g$ to $1.0 \times 10^{7} \mathrm{CFU} / \mathrm{g}$. L. rhamnosus did not inhibit S. aureus growth. The presence of lactic acid bacteria (LAB), mainly L. lactis, also showed evidences of inhibition of the enterotoxin $B$ production, and the staphylococcal enterotoxins concentration on the $15^{\text {th }}$ day was lower than the commercial kit threshold. Hence, the studied LAB may contribute to the sanitary quality of artisanal cheeses.
\end{abstract}

Keywords: cheese, Staphylococcus aureus, Lactococcus lactis, Lactobacillus rhamnosus, enterotoxin, sanitary quality

\section{INTRODUÇÃO}

Staphylococcus aureus é um contaminante frequente de alimentos, sobretudo em queijos artesanais, pois estes são elaborados com leite cru, e o microrganismo é um patógeno

Recebido em 27 de setembro de 2010

Aceito em 1 de julho de 2011

E-mail: biancaseridan@gmail.com

Apoio: FAPEMIG comumente encontrado na microbiota de leite oriundo de vacas com mastite. Além da contaminação proveniente do leite, a manipulação envolvida no processo de produção de queijos também é um fator de introdução de patógenos, pois o hábitat natural de $S$. aureus é a pele de mamíferos (Baird Parker, 1990) 
e $50 \%$ dos humanos saudáveis são portadores assintomáticos, apresentando esse microrganismo na pele das mãos, na orofaringe e no leito subungueal. Assim, o controle de mastite nos rebanhos leiteiros e as boas práticas de elaboração de queijos são essenciais para o controle da presença dessa contaminação.

Contaminações de alimentos por $S$. aureus são importantes devido ao fato de essa espécie ser capaz de produzir enterotoxinas que podem levar a quadro de intoxicação, causando desde simples diarreias a choque (Carmo, 2001; Giezendanner et al., 2009; Ostyn et al., 2010). O queijo é um alimento associado a quadros de intoxicação por enterotoxinas produzidas por $S$. aureus (Ostyn et al., 2009 ).

Sabe-se que, no Brasil, não há o hábito consolidado de procura pelo centro de saúde em casos de diarreias, salvo em casos graves ou persistentes. Esse aspecto poderia explicar a aparente baixa prevalência de intoxicações alimentares envolvendo $S$. aureus. A frequência de casos notificados em países com serviço de vigilância epidemiológica eficiente também está abaixo do esperado, considerando-se o hábito comum de consumo de queijos artesanais, produzidos com leite cru, como na França. Sabese também que há produção de enterotoxinas do tipo B (SEB) em queijos artesanais e que a presença de bactérias acidoláticas, que são normalmente encontradas em grande quantidade em leite cru e queijos artesanais, altera o comportamento de $S$. aureus (Guedes Neto et al., 2005; Resende et al., 2010). Assim, o objetivo deste trabalho foi estudar o comportamento desse contaminante na presença de Lactococcus lactis e Lactobacillus rhamnosus em queijos artesanais.

\section{MATERIAL E MÉTODOS}

Foram elaborados queijos frescos a partir de cinco lotes distintos de leite em pó desnatado Molico ${ }^{\circledR}$ (Nestlé, São Paulo, SP, Brasil) reconstituído a $10 \%$. Para inoculação no leite, duas culturas de bactérias acidoláticas, $L$. rhamnosus e L. lactis, isoladas de queijo de coalho artesanal e identificadas por PCR ARDRA16S-23S rDNA (Guedes Neto et al., 2005), bem como S. aureus FRI S-6, foram combinadas de cinco formas diferentes, compondo queijos distintos (tratamentos), além de um queijo-controle, em que não houve adição das bactérias citadas. No início do processo de elaboração, foram adicionados inóculos das culturas ao leite, em contagens a duas unidades logarítmicas acima das contagens encontradas por Guedes Neto et al. (2005) em queijos de coalho, considerando-se que o processo de produção de queijos é responsável pela redução das contagens em duas unidades logarítmicas. As contagens foram padronizadas por enumeração de microrganismos viáveis do cultivo, que foi de $10^{9} \mathrm{UFC} / \mathrm{mL}$ após 24 horas, em todas as culturas, e diluição de 10 vezes do cultivo de $S$. aureus e centrifugação a $313 \mathrm{G}$ e concentração do cultivo de L. lactis. A combinação dos inóculos está mostrada na Tab. 1

O leite utilizado para a produção dos queijos foi avaliado quanto à ausência de inibidores segundo o método TTC (Neal e Calbert, 1955) e de enterotoxinas estafilocócicas por ELISA, utilizando-se o kit VIDAS (Biomérieux), conforme indicações do fabricante. Leites livres desses contaminantes foram utilizados para a produção de queijos de $200 \mathrm{~g}$.

Os queijos foram armazenados entre 4 e $8^{\circ} \mathrm{C}$ e analisados no primeiro, quarto, sétimo e $15^{\circ}$ dias após a produção. As enumerações, em duplicata, das bactérias láticas foram feitas de acordo com Mac Fadin (1980), e a de Staphylococcus aureus segundo Lancette e Tatini (2001). Os valores obtidos para enumeração de microrganismos foram tratados com estatística não paramétrica. Para tal avaliação, o teste de Friedman foi utilizado com o auxílio do programa SAEG para Windows, a 5\% de significância. A pesquisa de enterotoxina estafilocócica B (SEB) foi realizada pelo ELISA, com o auxílio do kit VIDAS (Biomérieux). Portanto, este experimento foi realizado em um fatorial $6 \mathrm{X} 4$ (seis tipos de queijos e quatro tempos de análise), em cinco repetições. A atividade antagonista das bactérias acidoláticas frente ao $S$. aureus FRI S-6 em queijo foi determinada por um delineamento em blocos, representados pelos diferentes lotes de leite, com parcela subdividida, sendo as parcelas os seis tipos de queijo, e a subdivisão os diferentes tempos de análise. 
Viabilidade de Staphylococcus aureus...

Tabela 1. Combinação de inóculos de bactérias acidoláticas isoladas de queijo artesanal e Staphylococcus aureus isolado de surto de toxinfecção

\begin{tabular}{llc}
\hline Tratamento & Inóculo & Contagem (UFC) \\
\hline $1(\mathrm{C})$ & Salina tamponada $-1 \mathrm{~mL}$ & 0 \\
$2(\mathrm{LR})$ & Lactobacillus rhamnosus & $10^{9}$ \\
$3(\mathrm{LL})$ & Lactococcus lactis & $10^{10}$ \\
$4(\mathrm{SA})$ & Staphylococcus aureus & $10^{8}$ \\
$5(\mathrm{LRSA})$ & Lactobacillus rhamnosus & $10^{9}$ \\
& Staphylococcus aureus & $10^{8}$ \\
6 (LLSA) & Lactococcus lactis & $10^{10}$ \\
& Staphylococcus aureus & $10^{8}$ \\
\hline
\end{tabular}

\section{RESULTADOS E DISCUSSÃO}

Na Tab. 2 mostra-se o efeito da presença de $L$. rhamnosus e de L. lactis no comportamento de $S$. aureus, ao se comparar seu crescimento nos diferentes tratamentos. Quando analisados os tratamentos 4 (S. aureus) e 2 (L. rhamnosus) em relação ao tempo, a contagem de $S$. aureus foi decrescente, e a de L. rhamnosus crescente. Além disso, as contagens médias após 15 dias de produção foram $10^{6} \mathrm{UFC} / \mathrm{g}$ para $S$. aureus e $10^{7} \mathrm{UFC} / \mathrm{g}$ para L. rhamnosus, semelhantes aos resultados relatados em queijos de coalho artesanais (Sena, 2000; Guedes Neto et al., 2005) e queijo de minas artesanal da Serra da Canastra (Resende, 2010). As diferenças entre os tratamentos, porém, não foram significativas $(\mathrm{P}>0,05)$. Apesar de decrescente em relação ao tempo, o crescimento do contaminante do queijo sofreu pequenas alterações em presença da bactéria acidolática. No dia 1, o comportamento de $S$. aureus foi igual nos tratamentos 4 e 5 . Entretanto, no quarto dia, a queda na contagem de $S$. aureus, que ocorreu em ambos, foi mais acentuada no tratamento 5 do que no 4 , o que sugere a presença de fatores antagonistas do crescimento de $S$. aureus, produzidos por $L$. rhamnosus. Efeito interessante foi observado no sétimo dia após a produção, quando houve queda na contagem de $S$. aureus no tratamento $4 \mathrm{e}$ aumento no tratamento 5. Tais variações sugerem que L. rhamnosus não inibiu o crescimento de S. aureus. Essa observação é também vista nos valores obtidos no $15^{\circ}$ dia, quando a contagem de $S$. aureus foi mais baixa que a do dia 7. Entretanto, no tratamento 5, a contagem manteve-se mais elevada do que no tratamento 4. Sugere-se que, neste ponto, a queda do $\mathrm{pH}$ pode ter sido danosa para a cepa láctica e não para o contaminante, que resiste a $\mathrm{pH}$ entre 4 e 9,8 (Jay, 1996).
L. rhamnosus apresentou-se em menor número no tratamento 5 . Isso pode ser uma consequência de adaptação entre amostras em um mesmo ambiente, não representando antagonismo do contaminante frente à bactéria acidolática. Valores de contagem de L. lactis, nos tratamentos 3, 4, e 6, foram mais elevados que de L. rhamnosus, salientando-se que os inóculos foram elaborados com contagens distintas para cada amostra, sendo L. lactis encontrado em maior número em queijos artesanais brasileiros (Guedes Neto et al., 2005; Resende, 2010). Nos tratamentos 3 e 6, L. lactis apresentou perfil estável no decorrer do tempo, apresentando apenas uma queda em sua contagem no dia 4 , voltando a se estabilizar na ordem de $10^{8} \mathrm{UFC} / \mathrm{g}$, em ambos. Esse dado mostra a estabilidade e a resistência dessa amostra frente ao contaminante, sugerindo maior potencial para uso como inibidor do crescimento de $S$. aureus quando comparado a L. rhamnosus.

Staphylococcus aureus nos tratamentos 4 e 6 apresentou o mesmo padrão decrescente de contagem, com uma ressalva para a diferença entre os dias sete e 15 , o qual se apresenta menor no tratamento 6 do que no 4. Essa observação permite inferir que houve certo grau de antagonismo, sobretudo nos primeiros dias após a produção do queijo. O menor efeito antagonista entre os dias sete e 15 pode ser atribuído ao fato de, nesse período, já ter decorrido tempo suficiente para o $\mathrm{pH}$ ser reduzido a níveis próximos de 4,2 a 4,4, causando injúria ao $L$. lactis. Apesar de o pH mínimo suportado por $L$. lactis ser próximo do tolerado por Staphylococcus, aproximadamente 4,0, pode-se sugerir que o antagonismo aqui observado foi mais intenso nos primeiros dias, quando não houve produção excessiva de ácido lático a ponto de prejudicar a amostra de bactéria acidolática, mais sensível ao baixo $\mathrm{pH}$. 
Tabela 2. Médias de enumerações de Staphylococcus aureus, Lactobacillus rhamnosus, Lactococcus lactis (UFC/g) em queijos produzidos em laboratório, em cinco repetições, em relação ao tempo de estocagem por 15 dias a $4-8^{\circ} \mathrm{C}$

\begin{tabular}{|c|c|c|c|c|c|c|c|c|c|c|c|c|}
\hline \multirow[t]{3}{*}{ Tratamentc } & \multirow{2}{*}{\multicolumn{4}{|c|}{ Staphylococcus aureus }} & \multicolumn{5}{|c|}{ Lactobacillus rhamnosus } & \multicolumn{3}{|c|}{ Lactococcus lactis } \\
\hline & & \multicolumn{2}{|c|}{ Dia } & & \multicolumn{4}{|c|}{ Dia } & \multicolumn{4}{|c|}{ Dia } \\
\hline & D1 & D4 & D7 & D15 & D1 & D4 & D7 & D15 & D1 & D4 & D7 & D15 \\
\hline $1(\mathrm{C})$ & $<2 x$ & $<2 x$ & $<2 x$ & $<2 x$ & $<2 x$ & $<2 x$ & $<2 x$ & $<2 x$ & $<2 x$ & $<2 x$ & $<2 x$ & $<2 x$ \\
\hline & $10^{5} \mathrm{~b}$ & $10^{5} \mathrm{~b}$ & $10^{5} \mathrm{~b}$ & $10^{5} \mathrm{~b}$ & $10^{7} \mathrm{~b}$ & $10^{7} \mathrm{~b}$ & $10^{7} \mathrm{~b}$ & $10^{7} \mathrm{~b}$ & $10^{6} \mathrm{~b}$ & $10^{6} \mathrm{~b}$ & $10^{6} \mathrm{~b}$ & $10^{6} \mathrm{~b}$ \\
\hline 2(LR) & - & - & - & - & $\begin{array}{l}3,1 \mathrm{x} \\
10^{7} \mathrm{a}\end{array}$ & $\begin{array}{l}6,4 \mathrm{x} \\
10^{7} \mathrm{a}\end{array}$ & $\begin{array}{l}7,6 \mathrm{x} \\
10^{7} \mathrm{a}\end{array}$ & $\begin{array}{l}1,5 \mathrm{x} \\
10^{8} \mathrm{a}\end{array}$ & - & - & - & - \\
\hline 3(LL) & - & - & - & - & - & - & - & - & $\begin{array}{l}3,7 \mathrm{x} \\
10^{8} \mathrm{a}\end{array}$ & $\begin{array}{l}8,6 \mathrm{x} \\
10^{8} \mathrm{a}\end{array}$ & $\begin{array}{l}1,5 \mathrm{x} \\
10^{9} \mathrm{a}\end{array}$ & $\begin{array}{l}2,5 \mathrm{x} \\
10^{9} \mathrm{a}\end{array}$ \\
\hline $4(\mathrm{SA})$ & $\begin{array}{l}3,3 \mathrm{x} \\
10^{7} \mathrm{a}\end{array}$ & $\begin{array}{l}1,4 \mathrm{x} \\
10^{7} \mathrm{a}\end{array}$ & $\begin{array}{r}9,8 \mathrm{x} \\
10^{6} \mathrm{a}\end{array}$ & $\begin{array}{l}3,6 \mathrm{x} \\
10^{6} \mathrm{a}\end{array}$ & - & - & - & - & - & - & - & \\
\hline 5(LRSA) & $\begin{array}{l}2,1 \mathrm{x} \\
10^{7} \mathrm{ab}\end{array}$ & $\begin{array}{l}6,0 \mathrm{x} \\
10^{6} \mathrm{ab}\end{array}$ & $\begin{array}{l}7,6 \mathrm{x} \\
10^{6} \mathrm{ab}\end{array}$ & $\begin{array}{l}5,3 \mathrm{x} \\
10^{6} \mathrm{ab}\end{array}$ & $\begin{array}{l}2,6 \mathrm{x} \\
10^{7} \mathrm{a}\end{array}$ & $\begin{array}{l}6,2 \mathrm{x} \\
10^{7} \mathrm{ab}\end{array}$ & $\begin{array}{l}4,7 \mathrm{x} \\
10^{7} \mathrm{ab}\end{array}$ & $\begin{array}{l}6,7 \mathrm{x} \\
10^{7} \mathrm{ab}\end{array}$ & - & - & - & - \\
\hline 6(LLSA) & $\begin{array}{l}1,0 \mathrm{x} \\
10^{7} \mathrm{~b}\end{array}$ & $\begin{array}{l}9,2 \mathrm{x} \\
10^{6} \mathrm{ab}\end{array}$ & $\begin{array}{l}6,6 \mathrm{x} \\
10^{6} \mathrm{ab}\end{array}$ & $\begin{array}{l}5,4 \mathrm{x} \\
10^{6} \mathrm{ab}\end{array}$ & - & - & - & - & $\begin{array}{l}2,5 \mathrm{x} \\
10^{8} \mathrm{a}\end{array}$ & $\begin{array}{l}7,7 \mathrm{x} \\
10^{8} \mathrm{a}\end{array}$ & $\begin{array}{l}2,2 \mathrm{x} \\
10^{9} \mathrm{ab}\end{array}$ & $\begin{array}{l}2,5 \mathrm{x} \\
10^{9} \mathrm{a}\end{array}$ \\
\hline
\end{tabular}

Médias seguidas por letras minúsculas distintas na mesma coluna diferem entre si pelo teste de Friedman $(\mathrm{P}<0,05)$. C: controle; LR: Lactobacillus rhamnosus; LL: Lactococcus lactis; SA: Staphylococcus aureus.

A diferença observada ocorreu no primeiro dia após produção, em que houve antagonismo entre L. lactis e $S$. aureus no queijo 6 (LLSA). Entretanto, sugere-se pesquisa mais aprofundada da relação entre essas duas cepas para melhor compreensão das razões pelas quais se observou antagonismo apenas nesse momento. Os resultados deste trabalho corroboram os diversos relatos de alta contagem de $S$. aureus em queijos artesanais, ou mesmo industrializados, que variam de $10^{3}$ a $10^{8} \mathrm{UFC} / \mathrm{g}$ (Cerqueira et al., 1994; Sena, 2000; Guedes Neto et al., 2005).

L. rhamnosus e L. lactis apresentaram inibição do crescimento de $S$. aureus em testes in vitro (Guedes Neto et al., 2005). Considerando-se que nos dias quatro, sete e 15 deste estudo não houve inibição, esse fato chama atenção para a diferença entre os efeitos observados in vitro e no alimento.

Na pesquisa de enterotoxinas pelo kit VIDAS, os resultados foram expressos em valor de fluorescência relativa ou densidade óptica, obtido por cálculo de relação entre absorbância da amostra e absorbância do controle. O limite de detecção do teste é de 0,13 , isto é, acima desse valor é considerado positivo, e abaixo negativo. Os resultados dos valores de densidade óptica referentes à presença de enterotoxinas do tipo $\mathrm{B}$ (SEB) obtidos dos tratamentos 4,5 e 6 encontram-se na Fig. 1.

A Fig. 1 reflete o perfil padrão de produção da toxina SEB sem interferência de outra amostra bacteriana. Observa-se que houve maior concentração de SEB no dia sete do que nos dias quatro e 15. O aumento da concentração de SEB entre os dias quatro e sete, apesar de coincidir com um período em que houve redução no número de células viáveis de $S$. aureus no queijo, pode ser explicado pelo acúmulo de enterotoxina produzida na massa do queijo ou ainda pela maior eficiência das células na fase estacionária da curva logarítmica do crescimento para produção de enterotoxinas. Isso ocorreu entre cinco e seis horas no cultivo a $37^{\circ} \mathrm{C}$, mas pode ter demorado mais para se estabelecer no queijo devido à armazenagem sob refrigeração.

Todavia, a queda observada na concentração de toxina é o fato mais interessante, sendo possível que tenha havido fatores capazes de degradar a estrutura da enterotoxina já formada no queijo. Apesar de as enterotoxinas estafilocócicas serem resistentes à ação da maior parte das enzimas, inclusive à quimosina utilizada na produção do queijo e ao $\mathrm{pH}$ do leite, é possível haver sensibilidade a certas enzimas em determinado $\mathrm{pH}$, como é o caso da tripsina no $\mathrm{pH} 2,0$. A produção de enzima por bactérias láticas excluise neste caso, pois analisa-se o perfil ocorrido no tratamento 4 , no qual não houve inoculação de bactérias acidoláticas. Deve-se lembrar, porém, que o leite utilizado passou pelo processo de pasteurização, não era estéril e estava sujeito à ação de microrganismos psicrotróficos em momentos anteriores à pasteurização, que podem ter produzido enzimas proteolíticas no leite, e que persistiram no queijo (Varnan e Sutherland, 1994). 


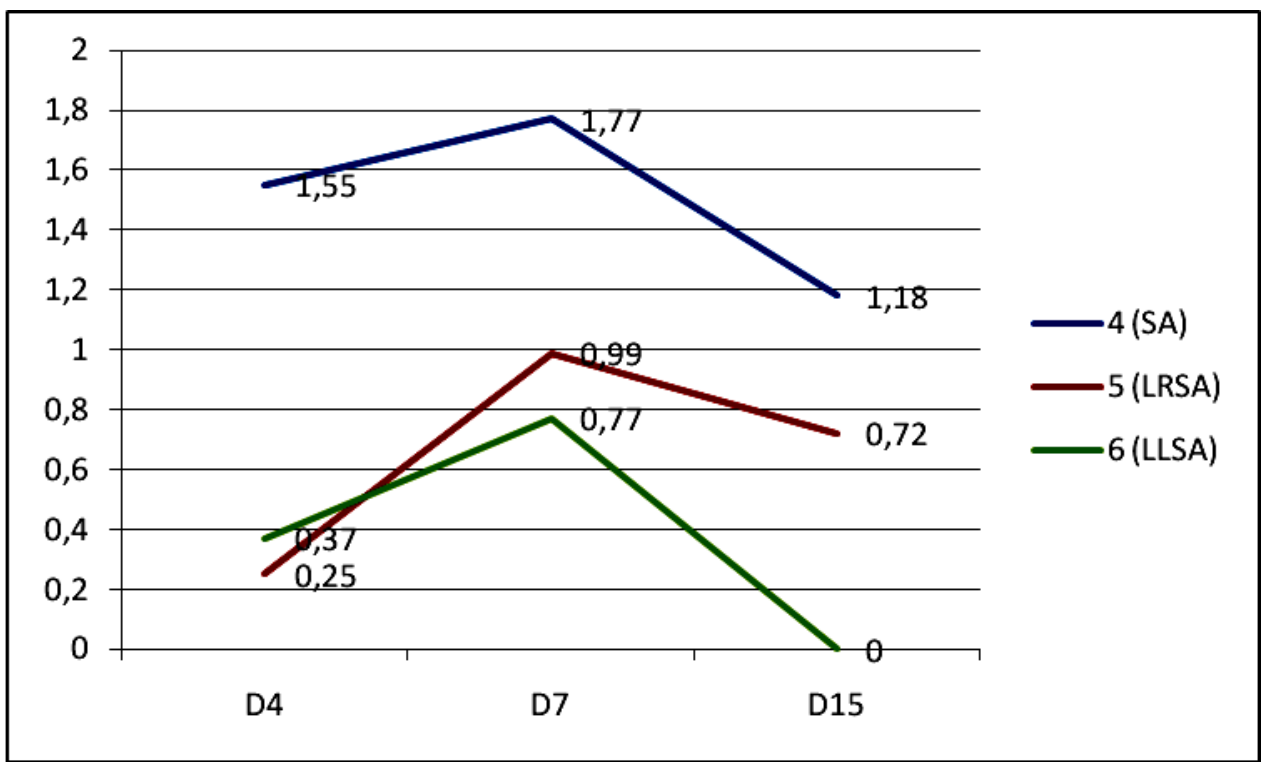

Figura 1. Níveis médios de enterotoxina SEB, em densidade óptica, em queijos elaborados em laboratório ao longo do tempo de estocagem de 15 dias a $4-8^{\circ} \mathrm{C}$.

SA: Staphylococcus aureus; LR: Lactobacillus rhamnosus; LL: Lactococcus lactis.

Embora seguindo o mesmo padrão do tratamento 4, os valores de absorbância foram menores no queijo do tratamento 6 , seguido pelos do tratamento 5. Ambos os queijos apresentaram menor concentração de enterotoxina $\mathrm{B}$, quando comparados com os do tratamento 4. No dia quatro, observou-se maior inibição da produção de enterotoxinas nos queijos do tratamento 5 quando comparados aos do tratamento 6. A diferença entre os dois foi mais expressiva no dia sete, quando a relação foi inversa, isto é, a redução no acúmulo de SEB foi maior no tratamento 6 que no 5, sugerindo maior inibição nessa fase por L. lactis. No dia sete, a redução na produção de SEB no tratamento 6 pode ser atribuída à redução da contagem de L. lactis, além dos outros fatores relativos à matriz alimentar, já discutidos.

Provavelmente, em razão do efeito cumulativo na concentração de toxinas, o efeito da inibição da produção de SEB por L. lactis é ainda melhor visualizado no dia 15 , no tratamento 6 , quando, somado ao efeito de inativação da toxina pela estrutura alimentar, atingiu densidade óptica igual a zero. Aqui, excluindo o fator limitante da inativação pela matriz do alimento, pode-se inferir que L. lactis foi capaz de inibir a produção de toxina por $S$. aureus. Pode-se dizer, também, que L. rhamnosus apresentou a mesma capacidade de inibição, porém em intensidade reduzida.

Salienta-se que, no dia sete, a inibição da produção de SEB nos queijos do tratamento 6 foi menor que a inibição observada nos do tratamento 5. Este dado pode estar relacionado ao fato de, nesse dia, a contagem de L. lactis ter se elevado, quando a de L. rhamnosus aumentou. Soma-se a isso o fato de, em ambos os casos, ter ocorrido redução na contagem de $S$. aureus. Neste momento, cabe a discussão dos fatores que levam à produção de enterotoxinas. A produção pode ter sido afetada pela presença de L. lactis bem como pela redução mínima de $S$. aureus.

A presença de bactérias acidoláticas nos queijos artesanais bem como o efeito de inativação de enterotoxinas provocado pela matriz alimentar do queijo é forte argumento para justificar o baixo índice de intoxicações alimentares por esse alimento no Brasil. Não se descarta o fato de haver subnotificação de casos às unidades públicas de saúde do país. Todavia, esse perfil de inativação de toxinas nos queijos, por si só, estimula investigações nesse alimento, em busca de formas mais efetivas de controle dessa 
intoxicação alimentar. A presença de L. lactis mostrou-se útil nessa busca.

\section{CONCLUSÕES}

A presença de L. lactis no queijo alterou o comportamento original de crescimento de $S$. aureus no primeiro dia após sua produção, e o $L$. rhamnosus não foi capaz de antagonizar o crescimento de $S$. aureus. As amostras de bactérias acidoláticas não reduziram a produção de enterotoxinas, porém ambas apresentaram potencial para a inibição, por pequena redução nos valores de DO nos queijos, sendo L. lactis a amostra que apresentou maior efeito.

\section{REFERÊNCIAS}

BAIRD-PARKER, A.C. The Staphylococci: an introduction. J. Appl. Bacteriol., v.19, v.69, p.1s-8s, 1990

CARMO, L.S. Produção e purificação em grande escala das enterotoxinas estafilocócicas SEA, SEB, $S E C_{2}$, SED e toxina TSST - 1 para uso em ensaios imuno-enzimáticos. 2001. 254f. Tese (Doutorado em Microbiologia) - Instituto de Ciências Biológicas, Universidade Federal de Minas Gerais, Belo Horizonte.

CERQUEIRA, M.M.O.P.; SOUZA, M.R.; FONSECA, L.M. Surto epidêmico de infecção alimentar envolvendo queijo fresco em Pará de Minas. Arq. Bras. Vet. Zootec., v.46, p.723-728, 1994.

GIESENDANNER, N.; MEYER, B.; GORT, M. et al. Raw milk-associated Staphylococcus aureus intoxication in children. Schweiss Arch Tierheilkd., v.7, p.329, 2009

GUEDES NETO, L.G.; SOUZA, M.R.; NUNES, A.C. et al. Atividade antagonista de bactérias isoladas de queijos de coalho artesanal e industrial frente a microrganismos indicadores. Arq. Bras. Med. Vet. Zootec. v.57, supl. 2, p.245-250, 2005.
JAY, J.M. Modern Food Microbiology. 2.ed. Nova York: Chapman \& Hall, 1996. 661p.

LANCETTE, G.A.; TATINI, S.R. Staphylococcus aureus In: DOWNES, F.R; KEITH, I.T.O. Compendium of Methods for the Microbiological Examination of Foods. 4ed. Washington, DC: American Public Health Association, 2001. p.387-403.

MacFADDIN, J.F. Biochemical tests for identification of medical bacteria. 2ed. Baltimore: Willians e Wilkins, 1980. 527p.

NEAL, C.E., CALBERT, H.E. The use of 2, 3, 5 triphenyltetrazolium chloride as a test for antibiotic substances in milk. J. Food Prot., v.38, p.629-633, 1955.

OSTYN, A.; DE BUYSER, M.L.; GUILLIER, F. et al. First evidence of a food poisoning outbreak due to staphylococcal enterotoxin type E, France. Euro Surveil, v.13, p.19528, 2009

RESENDE, M.F.S. Queijo Minas Artesanal da Serra da Canastra: influência da altitude e do nível de cadastramento das queijarias nas características físico-químicas e microbiológicas. 2010. 69f. Dissertação (Mestrado em Medicina Veterinária) Escola de Veterinária, Universidade Federal de Minas Gerais, Belo Horizonte.

SENA, M.J. Perfil epidemiológico, resistência a antibióticos e aos conservantes nisina e sistema lactoperoxidase de Staphylococcus sp. isolados de queijo coalho comercializado em Recife - PE. 2000. 75f. Dissertação (Mestrado em Medicina Veterinária) - Escola de Veterinária, Universidade Federal de Minas Gerais, Belo Horizonte.

VARNAN, A.H.; SUTHERLAND, J.P. Milk and milk products. Londres: Chapman \& Hall, 1994. 450p. 